\title{
TO STUDY THE APPLICATION OF NANOREFRIGERANT IN REFRIGERATION SYSTEM: A REVIEW
}

\author{
Parvinder Singh ${ }^{1}$ \\ ${ }^{\text {I}}$ PG Student, School of Mechanical Engineering, Lovely Professional University (LPU), Phagwara, Punjab, India
}

\begin{abstract}
In past time only refrigerants were used in refrigeration process and they were having a global warming coefficient at high level. Now, as time change the modern techniques are coming into existence with the help of them the refrigeration process become more efficient and safe as compare to previous in atmospheric prospective. This review paper is based on the nanotechnologies used in present time in refrigeration system like vapour compression refrigeration system, domestic refrigerator and air conditioner etc. The nano refrigerant is nothing but the combined form of nano particle with the refrigerant. The nanorefrigerant can be formed by two ways (1) by mixing nano particles with refrigerant in gaseous form, (2) by mixing nano particles to lubricant. We will combine different nano particles having the same diameter and same volume fraction with the lubricant to study the nature of thermo-physical properties in refrigeration process. There would be some parameters that can be studied by this experiment like energy consumption, heat transfer, cop etc.
\end{abstract}

Keywords: nano particles, nano refrigerant, heat transfer coefficient, COP, Energy consumption.

\section{INTRODUCTION}

The most common refrigerant in current time is R132a in all the refrigeration systems like vapour compression refrigeration system, domestic refrigerators and air conditioners. But the only problem with this type of refrigerant is they need the large amount of electric power. Now for the time demand we need something new that will be able to replace alternative refrigerant with some advanced thermo-physical properties like high heat transfer, low power consumption in order to make the refrigeration process more effective and efficient so that we will have a chance to save the environment. The new technology is being introduced in present time that is, nanotechnology by the help of technology nano refrigerants are form.

Nano refrigerant is nothing but the combination of nano particle to the refrigerant for the sake of better refrigeration process. As compared to alternative refrigerant the nano refrigerant has better heat transfer. We have seen some research has been done by taking the nano refrigerant and they have found better heat transfer and energy consumption. The nano particles like $\mathrm{AL}_{2} \mathrm{O}_{3}, \mathrm{CuO}$ AND $\mathrm{TiO}_{2}$. Now can be form some other nano refrigerant by combining the different nano particles of same size. If it is feasible than we can say that we can make better efforts to refrigeration processes. Refrigeration process will become more efficient and more effective.

\section{LITERATURE REVIEW}

Here are the applications of nano refrigerants. The researchers have found the advantages by using nano refrigerant in place of alternative refrigerant. They have proved that the nano refrigerant is more efficient as compared to refrigerant.
Guo-liang Ding [1] This paper determines the CFD simulation of vapour compression refrigeration system. The different modules of refrigeration system were designed to investigation and the simulation process. The further calculations of the refrigeration characteristics were summarized in detail.

Hao Peng et al. [2] Refrigeration characteristics were examined by the nano-refrigerant using the nano particles of $\mathrm{Cu}, \mathrm{Al}, \mathrm{Al}_{2} \mathrm{O}_{3}$ and $\mathrm{CuO}$. The nano-particles were used with a average diameter of $20 \mathrm{~nm}$. The R113 and R141b were the refrigerants which were mixed with the nano particles to perform the research work and to get the desire solution. RB68EP was the lubricating oil used in this experiment. The result was the comparison of nano-refrigerant with different concentration of nano particles which depicts that the pool boiling of nano-refrigerant increase by decrease of nanoparticle density.

V Timofeeva et al. [3] The nano-refrigerants are the new concept in field of refrigeration and air conditioning system and the affect of nano-particles is beneficial to us in terms of increasing thermo-physical properties of the refrigeration and air-conditioning system. The nano-particles were added to refrigerants with the different particle size and mole fraction so that the comparison can be made and the best combination can the depict for the sake of healthy environment.

R. Kumar et al. [4] There are some common refrigerants are used like R12, R22, R600, R600a and 134a. These were not as efficient as to decrease the power consumption. This was the reason behind the development of nano-refrigerant so that the power consumption can be reduced. In this paper,aluminium oxide nano refrigerant is used with the lubricant to reduce the power consumption. By using 
$\mathrm{Al}_{2} \mathrm{O}_{3}$ nano-refrigerant the heat transfer enhancement was determined numerically. In any refrigeration system if we want to increase the performance the system tha $n$ we have to increase the thermophysical properties of the refrigerants and that can be done by adding nano-particles to the refrigerant ultimately the heat transfer individuality will improve. It is found that the replacement of the refrigerant by the nano-refrigerant is feasible in refrigeration system. By the experimental setup we come to know that the freezing capacity increasedand power usage decrease to $15 \%$ by the replacement of POE oil with the mixture of mineral oil and aluminium particles.

N. Subramani et al. [5] This review tells about the R134a, which is the most commonly used refrigerant in domestic refrigeration and air conditioning equipments. If we want to improve the performance of these equipments then we have to add some nano-particles, keeping in mind the refrigeration process should be feasible and should provide us better output. The nano-refrigerant has to work normally in refrigeration system. The power usage is reduced by $25 \%$ if the nano-particles of the alumina oxide are mixed with mineral oil in place of POE oil .

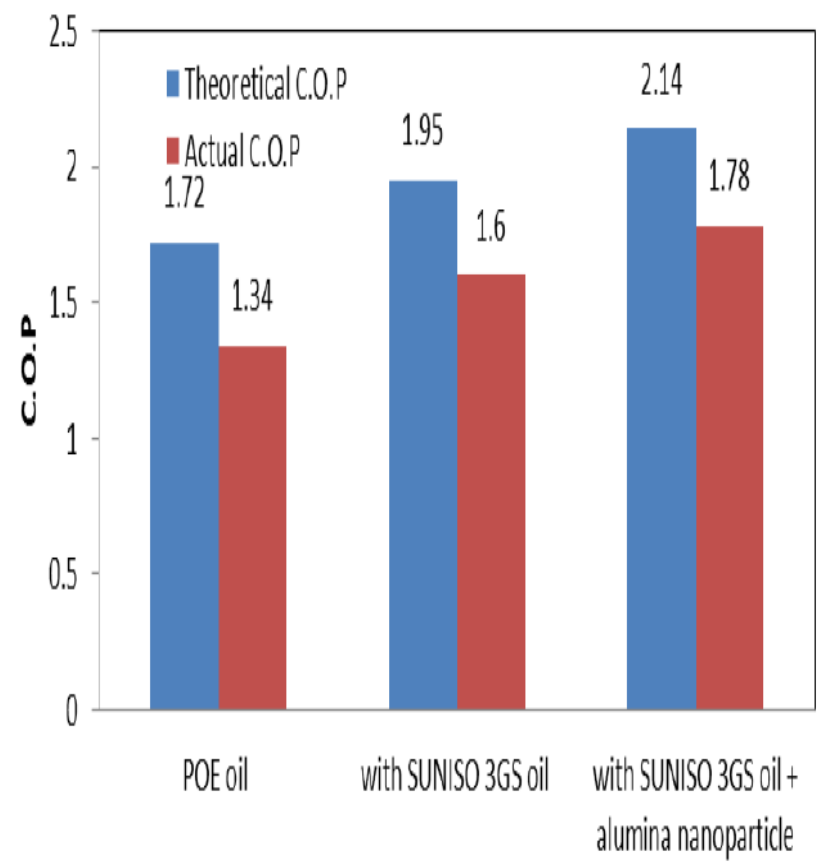

Chart -1: Comparison of COP in different cases

Sherifhadytaher [6] This paper calculated the evaporated heat transfer by using CuO-R134a nano-refrigerant in a vapour compression refrigeration system. The copper metal was used to construct the tube of the heat exchanger which was horizontal. The copper tube was used to evaporate the refrigerant and hot water was passed by the surrounding of this copper tube particle size was very small and the mole fraction by concentration was $0.05-1 \%$. The coming result was that it works normally in the system and the evaporated heat transfer was increased and it tends to increase with increase in $\mathrm{CuO}$ concentration at some instant after that it tends to decrease.

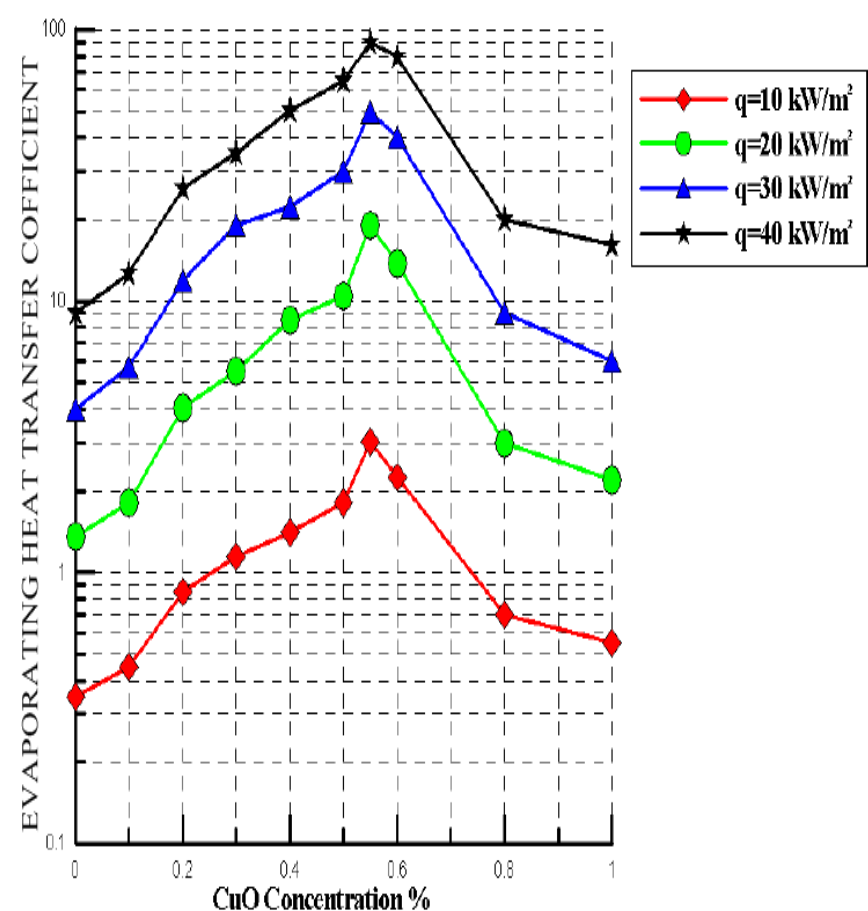

Chart -2: evaporating heat transfer coefficient at diff. $\mathrm{CuO}$ concentration

D. Sendil Kumar et al [7] VCRS were examined by the nano-refrigerant $\mathrm{Al}_{2} \mathrm{O}_{3}$ with $\mathrm{PAG}$ oil. The setup was made to calculate the freezing capacity and energy use for the refrigeration process. It was found that the replaced nanorefrigerant work safely in the system and there was no harm produced during refrigeration and it is a feasible process. By using $0.2 \%$ volume fraction the heat transfer rate increased upto a good instant and the energy usage is reduced by $10.2 \%$.

I.M. Mahbubul et al. [8] The nano-refrigerant if nothing but the mixture of nano-particles and the refrigerant that is as same as mixture of nano-particles with fluids. The purpose of using nano-refrigerant in place of refrigerant is only the much betterheat transfer. The mole fraction of the volume is the important factor to keep in mind. We are bound to use the relevant mole fraction of the nano-particles to get the desired output. This paper concludes that the low volume fraction or nao-particle are best to attain good refrigeration performance.

J.E. Parise et al. [9] A simulation model was developed for the performance prediction of a vapor compression heat pump using nano-refrigerants as condenser coolants. The model was with reciprocating compressor, thermostatic expansion valve and counter-flow double-tube condenser and evaporator. The compressor is characterized (input data) by its swept volume, shaft speed and isentropic and volumetric efficiency curves, and the expansion device, by the evaporator superheat. The condenser is divided into three zones, superheating, condensing and subcooling. Likewise, the evaporator is divided into the boiling and superheating zones. The heat exchangers are characterized (input data) by their geometry (inner and outer tube 
diameters and length). Operational input data also include condenser subcooling and heat transfer fluids (condenser and evaporator) mass flow rates and inlet thermodynamic states. Solution of the system provides the cycle overall thermal performance, as well as condensing and evaporating pressures and the thermodynamic states of refrigerant and heat transfer fluids at all points of the cycle. Preliminary results were obtained for the simulation of a $19 \mathrm{~kW}$ nominal capacity heat pump. A $5.4 \%$ increase in the heating coefficient of performance, for a typical operating condition, was predicted for a nano-particles volume fraction of $2 \%$.

Lixin Cheng [10] This paper is focusing upon the recent patents in the nano-refrigerant used technologies and their improvement in the different refrigeration properties. They found a large number of patents in the heat transfer in the refrigeration system. By this paper the further developments in nano-refrigerants are highlighted with the best characteristics.

Subramani et al. [11] The most researches were done by using R134a refrigerant and in present time it is again under the consideration of researchers but with some nano technology. This paper shows that when R134a was investigated with $\mathrm{TiO}_{2}$ nano-particle in place of SUNISO $3 \mathrm{GS}$ oil the result was very effective, the COP was increased by $20 \%$ and the power consumption was reduced by $15.4 \%$.

Dr. R.S. Mishra [12] In this paper, vapour compression refrigeration system was modified in which the refrigerant and the nano-fluid both were used as coolant. These were used in separate circuits. $\mathrm{Al}_{2} \mathrm{O}_{3}$ nano-fluid was taken into the consideration. On the basis of the performance of this refrigeration system it was quite easy to design Evaporator, condenser, throttle valve, compressor for VCRS. The same model further simulated in CFD analysis to solve the system of equation and by the simulation it is clearly depicted the performance improvement from $17-20 \%$.

T. Coumaressin et al. [13] When we think about the refrigeration system and air-conditioning system one term comes in mind that is heat transfer. The efficient and widely used refrigerant is HFC R134a in the air-conditioning system and domestic refrigeration system. The drawback of HFC R134a is, its high global warming potential. If we add nano-particles to the refrigerant than we can increase the performance characteristics of the system that will directly lead us to safe environment as well. This paper is on the CFD analysis of the vapour compression system on FLUENT software using CuO-R134a nano-refrigerant. It was found that the nano-refrigerant work efficiently and normally in the system. Al last result indicates that the evaporating heat transfer is improved.

Fadhilah et al. [14] We have found that the nanorefrigerants have been used in order ti increase the heart transfer and also to reduce the power consumption. It is also found that the researches were done with low concentration of nano-particles to increase the thermo-physical properties up-to a better extent. When we talk about nano-refrigerant thermal conductivity we come to know that the amount of literature is very less in this field. The study shows that the $\mathrm{Al}_{2} \mathrm{O}_{3}$ nano-particle used with $\mathrm{R} 134 \mathrm{a}$ reduce the energy consumption $10.32 \%$ while $\mathrm{TiO}_{2}$ nano-particles with R600a reduce amount of energy use to $5.94 \%$ with a concentration of $0.1 \mathrm{~g} / \mathrm{L}$.

\section{CONCLUSION}

Nano refrigerant is an advanced mode of heat transfer in refrigeration system. It was shown already by the researches that were held in the past. Now the new thing will be done by mixing different nano particles of the same size and shape so that the effect can be studied out. The motive to do this experimentation is to increase the heat transfer and other thermo physical properties.

\section{ACKNOWLEDGEMENTS}

It's a great opportunity comes into existence. We are using the conceptual knowledge to do some useful work for the sake of our society. And yes, it is not possible with the help of mentor Mr. Kapil Sharma. We are glad to work with him.

\section{REFERENCES}

[1]. Guo-liang Ding, Recent developments in simulation techniques for vapour-compression refrigeration systems International Journal of Refrigeration 30 (2007) (11191133)

[2]. Hao Peng, Guoliang Ding, Haitao Hu, Influences of refrigerant-based nanofluid composition and heating condition on the migration of nanoparticles during pool boiling. Part I: Experimental measurement, international journal of refrigeration 34 (2011) (1823-1832)

[3]. Elena V Timofeeva, Wenhua Yu, David M France, Dileep Singh3, Jules L Routbort, Nanofluids for heat transfer: an engineering approach Timofeeva et al. Nanoscale Research Letters 2011, 6:182

[4]. R. Reji Kumar ,K. Sridhar , M.Narasimha, Heat transfer enhancement in domestic refrigerator using R600a/mineral oil/nano-A12O3 as working fluid, International Journal of Computational Engineering, Vol, 03,Issue, 4.

[5] N. Subramani 1, M. J. Prakash, Experimental studies on a vapour compression system using nanorefrigerants, International Journal of Engineering, Science and Technology, Vol. 3, No. 9, 2011, pp. 95-102

[6]. Eed Abdel-Hafez Abdel-Hadi, Sherif Hady Taher Abde Hamid Mohamed Torki2 and Samar Sabry Hamad, Heat transfer analysis of vapour compression system using Nano CuO-R134a, 2011 International Conference on Advanced Materials Engineering IPCSIT vol.15 (2011) (C) (2011) IACSIT Press, Singapore

[7]. D. Sendil Kumar1, Dr. R. Elansezhian, Experimental Study on A12O3-R134a Nano Refrigerant in Refrigeration System, International Journal of Modern Engineering Research, Vol. 2, Issue. 5, Sep.-Oct. 2012 pp-3927-3929

[8]. I.M. Mahbubul ,R. Saidur and M.A. Amalina, Investigation of viscosity of R123-TIO2 Nanorefrigernt, International Journal of Mechanical and Materials Engineering, Vol. 7 (2012), No. 2, 146-151. 
[9]. José Alberto Reis Parise, Ricardo Fernando Paes Tiecher, A Simulation Model for the Application of Nanofluids as Condenser Coolants in Vapor Compression Heat Pumps, International Refrigeration and Air Conditioning Conference at Purdue, July 16-19, 2012, 2531 [10]. Lixin Cheng, Lei Liu, Boiling and two-phase flow phenomena of refrigerant-basednanofluids: Fundamentals, applications and challenges, International Journal of Refrigeration 36 (2013) (421-446)

[11]. Subramani.N, Aswin Mohan, Dr.Jose Prakash.M, PERFORMANCE STUDIES ON A VAPOUR COMPRESSION REFRIGERATION SYSTEM USING NANO-LUBRICANT, International Journal of Innovative Research in Science, Engineering and Technology An ISO 3297: 2007 Certified Organization, Volume 2, Special Issue 1, December 2013

[12]. Prof(Dr) R S Mishra, Methods for improving Thermodynamic performance of vapour compression refrigeration system using twelve eco friendly refrigerants refrigerants in primary circuit and nano fluid in secondary, International Journal of Emerging Technology and Advanced Engineering Website: www.ijetae.com (ISSN 2250-2459, ISO 9001:2008 Certified Journal, Volume 4, Issue 6, June 2014)

[13]. $\mathrm{T}$ Coumaressin and $\mathrm{K}$ palaniradja, Performance analysis of a refrigeration system using nano fluid, International Journal of Advanced Mechanical Engineering. ISSN 2250-3234 Volume 4, Number 4 (2014), pp. 459-470 [14]. S A Fadhilah, R S Marhamah and A H M Izzat, Copper oxide nano particles for advance refrigerant thermo physical properties : mathematical modelling, Hindawi Publishing Corporation Journal of Nanoparticles Volume 2014, Article ID 890751, 5 pages

\section{BIOGRAPHY}

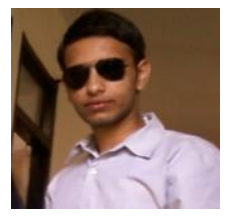

Mr. Parvinder Singh, PG Student, Lovely Professional University, Jalandhar (Punjab) 